\title{
Patient With COPD-Asthma Overlap Detected by Sputum Eosinophilia
}

\author{
Glenda Ernst ${ }^{\mathrm{a}, \mathrm{c}}$, Bethy Camargo ${ }^{\mathrm{b}}$, Eduardo Borsini ${ }^{\mathrm{a}}$, Martin Bosio ${ }^{\mathrm{a}}$, Alejandro Iotti ${ }^{\mathrm{a}}$, \\ Alejandro Salvado ${ }^{\mathrm{a}}$
}

\begin{abstract}
A 70-year-old man was diagnosed with COPD. He reported symptoms of nocturnal shortness of breath, cough and wheezing in the last time; however, he had never had asthma. Despite the treatment and the pulmonary rehabilitation, our patient referred the persistence of the symptoms. In a research screening of differential cellular count in the induced sputum in patients with COPD, we found that his sample showed high percentage of eosinophils. Due to this finding, we started to study him. Peripheral eosinophilia, FeNO and $\operatorname{IgE}$ were also found to be elevated. In the last years, he had chronic rhinitis. Besides, the reversibility of lung function after bronchodilators was observed. The algorithms to diagnose asthma-COPD overlap syndrome (ACOS) include positive bronchodilator response, sputum eosinophilia or previous diagnosis of asthma, high IgE and/or history of atopy. Our patient was diagnosed with ACOS, and the sputum findings have contributed to the modification of his treatment and lead to a clinical improvement and reduction of the symptoms.
\end{abstract}

Keywords: Asthma-COPD overlap; Eosinophils; Sputum sample

\section{Introduction}

Global Initiative for Asthma (GINA) and Global Initiative for Chronic Obstructive Lung Disease (GOLD) guidelines have defined the asthma-COPD overlap syndrome (ACOS) as an illness characterized by persistent airflow limitation with several features associated with asthma and others associated with COPD [1]. However, the heterogeneity of the airway inflammation is present in asthma-COPD overlap, therefore ACOS could present different phenotypes defined by eosinophilic or neutrophilic pattern [2]. It has been previously described that

Manuscript accepted for publication October 20, 2015

aHospital Britanico de Buenos Aires, Argentina

${ }^{b}$ Hospital Ricardo Gutierrez, Buenos Aires, Argentina

${ }^{\mathrm{c} C}$ Corresponding Author: Glenda Ernst, Hospital Britanico de Buenos Aires, Pulmonary Lab, Perdriel 74, $1^{\circ}$ Floor, CP 1280AEB, Ciudad de Buenos Aires, Argentina. Email: glenda.uba@gmail.com

doi: http://dx.doi.org/10.14740/jmc2348w
asthma-COPD overlap has prevalence of around $2 \%$ of adult population or $20 \%$ of COPD patients [3].

Diagnosis of ACOS is important because patients with ACOS have more exacerbations and they are more severe than subjects with either asthma or COPD alone [4].

We presented a COPD patient, without history of asthma, which was diagnosed with ACOS due to high eosinophilia in sputum. The proper diagnosis has contributed to the modification of the standard treatment, leading to a clinical improvement in this patient.

\section{Case Report}

The patient is a 70-year-old man with a body mass index of 24.9 and smoking history (116 pack/year). He was diagnosed with COPD (GOLD-1) and emphysema (Fig. 1). He presented dyspnea (mMRCII), low diffusion capacity of carbon monoxide (DLCO: 29\%) (Table 1), 6-min walking test with 352 $\mathrm{m}$ walked and desaturation (94-90\%, Borg: 0-1). The patient started pulmonary rehabilitation twice a week.

$\mathrm{He}$ had a right pneumonia and empyema in 2009, which was treated with thoracic drainage, showing PPD and pleural effusion culture negatives with normal pleural biopsy. Since 2013, he is having chronic rhinitis treated with aqueous mometasone spray.

Despite the COPD treatment with budesonide, formoterol, glycopyrronium, indacaterol and ipratropium nebulized, he reported symptoms of nocturnal shortness of breath, cough and wheezing in the last 2 years. He had never had asthma symptoms.

In the screening study, the induced sputum sample was performed according to the criteria previously described [5]. A rise in percentage of the sputum eosinophilia was found (Fig. 2). Differential sputum count showed $12.8 \%$ macrophages, $49.7 \%$ neutrophils, $35 \%$ eosinophils, $0 \%$ lymphocytes and $2.5 \%$ epithelial cells. These findings contributed to the support of ACOS as diagnosis, and then additional studies were performed. Peripheral eosinophilia $\left(11 \%, 990 \mathrm{~mm}^{3}\right)$ was also found with the rest of parameters in a normal range. The patient showed FeNO of $120 \mathrm{ppb}$ and IgE of $248 \mathrm{UI}$. Other diagnoses associated with eosinophilia such as parasitosis, allergic bronchopulmonary aspergillosis or Churg-Strauss syndrome were discarded.

Owing to these findings like eosinophilia, reversibility 

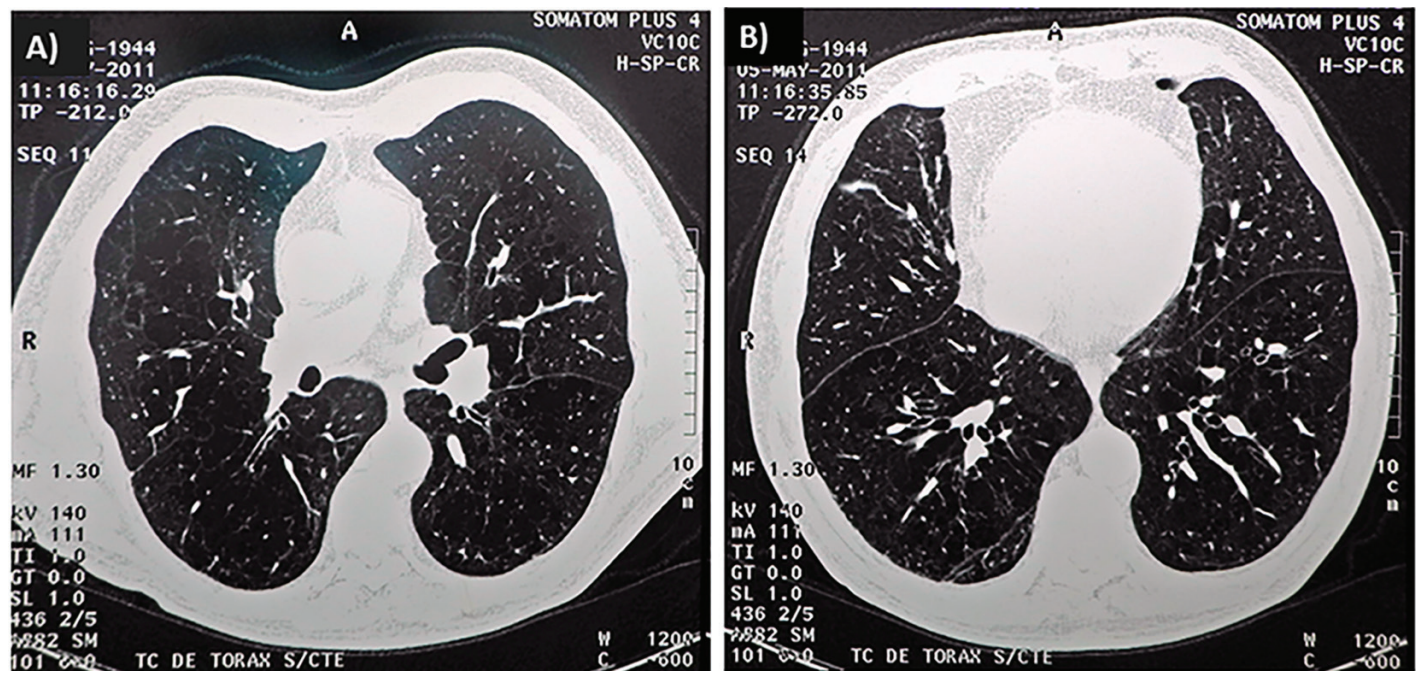

Figure 1. Axial CT image that shows areas with decreased attenuation and emphysema $(A)$ and finally thickening of the septa (B).

of airflow, increased levels of FeNO and IgE, we decided to change the treatment. The patient began to receive glycopyrronium, indacaterol and mometasone $(800 \mu \mathrm{g}$ using inhaled capsule during 2 weeks and then he began to use $400 \mu \mathrm{g}$ ). Six weeks later, the patient underwent a control. Decreases in the level of FeNO (40 ppb) and in the percentage of sputum eosinophils $(7.6 \%)$ were observed. Moreover, at the clinical examination, he did not show wheezing, and he referred an improvement of the nocturnal symptoms. Currently, this patient follows with this pharmacological therapy and he remains clinically stable.

\section{Discussion}

It was previously described that a subgroup of COPD patients required treatment with inhaled corticosteroids (ICS)/longacting beta agonist (LABA) in order to improve the long-term management for the illnesses [6].

ACOS has been identified by the features that it shares with both asthma and COPD. These include COPD patients with emphysema and partially reversible airflow obstruction, with or without environmental allergies, reduced DLCO and/ or sputum eosinophilia and asthma patients who present par-

Table 1. Pulmonary Lung Functions Test

\begin{tabular}{lll} 
& L & Percentages \\
\hline FEV1 pre & 2.11 & 74 \\
FEV1 post & 2.34 & 86 \\
FVC pre & 4.09 & 105 \\
FVC post & 4.09 & 105 \\
FEV1/FVC & & 51 \\
DLCO & & 29 \\
DLCO corrected & & 29 \\
\hline
\end{tabular}

tially reversible airflow obstruction with or without emphysema or DLCO $<80 \%$ of teoric value [7]. Recently new diagnosis algorithm has been proposed. It included two major or one major and two minor criteria. The major criteria are very positive bronchodilator response $(>400 \mathrm{~mL}$ and $15 \%$ in FEV1), sputum eosinophilia or previous diagnosis of asthma. The minor criteria are high IgE, previous history of atopy or positive bronchodilator test $(>200 \mathrm{~mL}$ and $12 \%$ in FEV1) in at least two opportunities [8].

Asthma-COPD overlap leads to health status impairment, increased exacerbations, hospitalizations and mortality. Moreover, in young patients ( 20 - 44 years old) with ACOS, the diagnosis of ACOS was associated with an increase of the hospitalization rate and the number of hospital admissions compared with severe asthma population [9].

The relevance of recognizing the ACOS in patients with COPD, who have eosinophilic inflammation, is the change of habitual treatment. It has been found that these patients

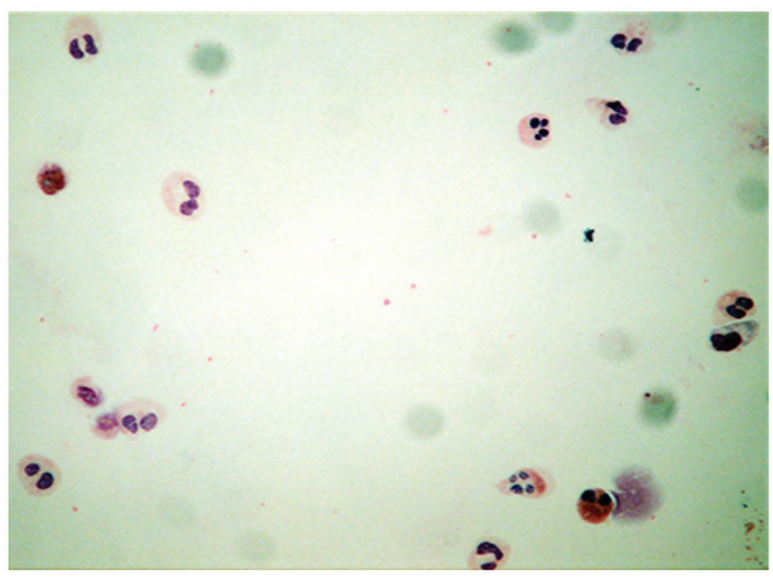

Figure 2. Induced sputum smear showing numerous eosinophils (MayGrunwald, Giemsa stain, original magnification $\times 400$ ). 
presented improvement in FEV1 after receiving ICS, which suggested that sputum eosinophilia could be a predictor of response of corticosteroids.

The induced sputum is a non-invasive processing. A sensitivity of $82.4 \%$ and a specificity of $84.8 \%$ of eosinophilia sputum have been reported for detection of asthma-COPD overlap, using a cut-off value of $2.5 \%$ [10].

Although induced sputum cell count is a non-invasive technique, it is not usually performed to study COPD patients. Nevertheless, in our patient, the eosinophilic pattern in the sputum sample contributed to the recognition of the ACOS.

\section{Acknowledgement}

We are especially grateful to Dr. Alvar Agusti (Hospital Clinic, University of Barcelona, Barcelona, Spain) by reading and correcting the manuscript with such dedication.

\section{Conflict of Interest}

The authors have not conflict of interest to declare.

\section{Grant}

This work was supported by grant from ROEMMERS Foundation.

\section{References}

1. Global Initiative for Asthma (GINA). Diagnosis of Diseases of Chronic Airflow Limitation: Asthma, COPD and Asthma-COPD Overlap Syndrome (ACOS): Global Strategy for Asthma Management and Prevention. 2014.
2. Gibson PG, McDonald VM. Asthma-COPD overlap 2015: now we are six. Thorax. 2015;70(7):683-691.

3. de Marco R, Pesce G, Marcon A, Accordini S, Antonicelli L, Bugiani M, Casali L, et al. The coexistence of asthma and chronic obstructive pulmonary disease (COPD): prevalence and risk factors in young, middle-aged and elderly people from the general population. PLoS One. 2013;8(5):e62985.

4. Gibson PG, Simpson JL. The overlap syndrome of asthma and COPD: what are its features and how important is it? Thorax. 2009;64(8):728-735.

5. Paggiaro PL, Chanez P, Holz O, Ind PW, Djukanovic R, Maestrelli P, Sterk PJ. Sputum induction. Eur Respir J Suppl. 2002;37:3s-8s.

6. Akamatsu K, Matsunaga K, Sugiura H, Koarai A, Hirano T, Minakata Y, Ichinose M. Improvement of Airflow Limitation by Fluticasone Propionate/Salmeterol in Chronic Obstructive Pulmonary Disease: What is the Specific Marker? Front Pharmacol. 2011;2:36.

7. Hardin M, Silverman EK, Barr RG, Hansel NN, Schroeder JD, Make BJ, Crapo JD, et al. The clinical features of the overlap between COPD and asthma. Respir Res. 2011;12:127.

8. Barrecheguren M, Esquinas C, Miravitlles M. The asthma-chronic obstructive pulmonary disease overlap syndrome (ACOS): opportunities and challenges. Curr Opin Pulm Med. 2015;21(1):74-79.

9. Yamauchi $Y$, Yasunaga $H$, Matsui $H$, Hasegawa W, Jo T, Takami K, Fushimi K, et al. Comparison of inhospital mortality in patients with COPD, asthma and asthma-COPD overlap exacerbations. Respirology. 2015;20(6):940-946.

10. Kitaguchi Y, Komatsu Y, Fujimoto K, Hanaoka M, Kubo K. Sputum eosinophilia can predict responsiveness to inhaled corticosteroid treatment in patients with overlap syndrome of COPD and asthma. Int J Chron Obstruct Pulmon Dis. 2012;7:283-289. 